\title{
Leptin levels in different forms of Chagas' disease
}

F. Fernandes ${ }^{1}$, S. Dantas ${ }^{1}$, B.M. Ianni ${ }^{1}$, F.J.A. Ramires ${ }^{1}$, P. Buck ${ }^{1}$, V.M.C. Salemi ${ }^{1}$, H.F. Lopes ${ }^{2}$ and C. Mady ${ }^{1}$
${ }^{1}$ Unidade de Miocardiopatias, ${ }^{2}$ Unidade de Hipertensão, Instituto do Coração, Faculdade de Medicina, Universidade de São Paulo, São Paulo, SP, Brasil

\begin{abstract}
Correspondence
F. Fernandes

Instituto do Coração

Faculdade de Medicina, USP

Av. Dr. Eneas C. Aguiar, 44

05403-000 São Paulo, SP

Brasil

Fax: +55-11-3069-5346

E-mail: fabio.fernandes@incor.usp.br

Publication supported by FAPESP.
\end{abstract}

$\ldots \ldots \ldots \ldots \ldots \ldots$

Received September 19, 2006 Accepted July 2, 2007

\section{Abstract}

Leptin is produced primarily by adipocytes. Although originally associated with the central regulation of satiety and energy metabolism, increasing evidence indicates that leptin may be an important mediator in cardiovascular pathophysiology. The aim of the present study was to investigate plasma leptin levels in patient with Chagas' heart disease and their relation to different forms of the disease. We studied 52 chagasic patients and 30 controls matched for age and body mass index. All subjects underwent anthropometric, leptin and $\mathrm{N}$ terminal pro-brain natriuretic peptide (NT-proBNP) measurements and were evaluated by echocardiography, 12-lead electrocardiogram (ECG), and chest X-ray. All patients had fasting blood samples taken between 8:00 and 9:00 am. Chagasic patients were divided into 3 groups: group I (indeterminate form, IF group) consisted of 24 subjects with 2 positive serologic reactions for Chagas' disease and no cardiac involvement as evaluated by chest X-rays, ECG and twodimensional echocardiography; group II (showing ECG abnormalities and normal left ventricular systolic function, ECG group) consisted of 14 patients; group III consisted of 14 patients with congestive heart failure (CHF group) and left ventricular dysfunction. Serum leptin levels were significantly lower $(\mathrm{P}<0.001)$ in the CHF group $(1.4 \pm 0.8 \mathrm{ng} / \mathrm{mL})$ when compared to the IF group $(5.3 \pm 5.3 \mathrm{ng} / \mathrm{mL})$, ECG group $(9.7 \pm 10.7 \mathrm{ng} / \mathrm{mL})$, and control group $(8.1 \pm 7.8 \mathrm{ng} / \mathrm{mL})$. NT-proBNP levels were significantly higher $(\mathrm{P}<0.001)$ in the CHF group $(831.8 \pm 800.1 \mathrm{pg} / \mathrm{mL})$ when compared to the IF group $(53.2 \pm$ $33.3 \mathrm{pg} / \mathrm{mL}), \mathrm{ECG}$ group $(83.3 \pm 57.4 \mathrm{pg} / \mathrm{mL})$, and control group (32 $\pm 22.7 \mathrm{pg} / \mathrm{mL}$ ). Patients with Chagas' disease and an advanced stage of CHF have high levels of NT-ProBNP and low plasma levels of leptin. One or more leptin-suppressing mechanisms may operate in chagasic patients.

Chagas' disease is an important public health disorder in Latin America. It is an infectious disease caused by the protozoan parasite, Trypanosoma cruzi. Up to $60 \%$ of infected patients have no evidence suggest-
Key words

- Chagas' disease

- Leptin

- Heart failure

- Left ventricular failure

..................... (n. ing cardiovascular or gastrointestinal involvement. These individuals are thought to have what is known as the indeterminate form of the disease (1). Previous longitudinal studies of such patients have revealed percentages 
of electrocardiographic changes ranging from 23 to $38 \%$ during long-term follow-up $(2,3)$. Cardiac involvement is the most noticeable manifestation when congestive heart failure (CHF) appears in the late phase of cardiomyopathy.

Leptin is a 167 -amino acid product of the $o b$ gene, which is produced primarily by adipocytes. Although originally associated with the central regulation of satiety and energy metabolism, increasing evidence now indicates that leptin may be an important mediator in cardiovascular pathophysiology (4). In addition to its direct effects on energy metabolism and caloric intake, leptin has distinct effects on the cardiovascular system leading to vascular remodeling, oxidative stress, neointima formation, as well as cardiomyocyte hypertrophy $(5,6)$. Several circulatory effects appear to be mediated by an interaction with the sympathetic nervous system and the major reflexogenic area involved in cardiovascular homeostatic control (5). Metabolic abnormalities in chronic heart failure include several local and systemic paracrine/endocrine systems and lead to an imbalance between catabolic and anabolic mechanisms. Leptin contributes to the modulation of metabolism, breathing control and inflammation, all of which have been linked to cardiovascular health and disease (6).

Previous studies have shown contradictory results in patients with heart failure. In a study by Schulze et al. (7), patients with advanced CHF had elevated serum levels of leptin and its soluble receptor. This finding indicates that leptin may participate in the catabolic state leading to the development of cardiac cachexia in the course of CHF. Conversely, Richartz et al. (8) observed that plasma leptin concentrations were significantly lower in CHF patients compared to controls.

The peculiar involvement of the autonomic nervous system in Chagas' heart disease causes abnormalities in neurogenic car- diovascular control before left ventricle dysfunction or overt heart failure even appears (9). Chagas' cardiomyopathy has several specific characteristics such as early cardiac denervation and neurohormonal abnormalities that differ from those observed in other cardiomyopathies. This different pathophysiology suggests that some metabolic abnormalities might be different in chagasic patients.

Although there is an extensive literature regarding the action of leptin in the cardiovascular system in normal and congestive heart failure subjects, there is a lack of information regarding the action of leptin in the cardiovascular system of chagasic patients with different forms of the disease.

The aim of the present study was to investigate plasma leptin levels and their relation to different forms of Chagas' disease, because the increasing understanding of the role played by natriuretic peptides and leptin opens new frontiers in the care of chagasic heart failure.

Fifty-two patients with a diagnosis of Chagas' disease were recruited prospectively from the Cardiomyopathy Clinical Unit of the Heart Institute (InCor), University of São Paulo Medical School. The inclusion criteria were patients with 2 positive serologic reactions for Chagas' disease, age over 18 years, both genders, and with different forms of Chagas' disease. The exclusion criteria were myocardial infarction (evaluated by $\mathrm{Q}$ waves on an electrocardiogram (ECG), segmental dysfunction by 2-dimensional echocardiography), valvar disease (evaluated by clinical examination and by Doppler echocardiography), and hypertension.

The chagasic patients were divided into 3 groups: group I, indeterminate form, comprised 24 subjects with 2 positive serologic reactions for Chagas' disease and no cardiac involvement as defined by chest X-rays, 12 lead ECG and 2-dimensional echocardiography. All patients had normal barium stud- 
ies of the esophagus and the colon. Group II, ECG group, consisted of 14 patients with normal left ventricular (LV) function showing right or left bundle branch block, left anterior fascicular block, diffuse St-T changes, ventricular premature beats that may be multiform, and runs of non-sustained ventricular tachycardia on the ECG. Group III, dysfunction group, comprised 14 patients with symptoms of $\mathrm{CHF}$ and $\mathrm{LV}$ dysfunction evaluated by ECG. The control group consisted of 30 healthy individuals.

All patients signed a written consent form, and the Ethics Committee of the Heart Institute, University of São Paulo Medical School, approved the study.

All subjects underwent anthropometric measurements including assessment of body mass index (BMI).

Serum leptin was measured by a solid phase two-site immunofluorometric assay using monoclonal antibodies produced in the Fleury Laboratory (São Paulo, SP, Brazil). BALB-c mice were immunized with recombinant human leptin (Eli Lilly \& Co., Indianapolis, IN, USA). Two fusions were made and a high-affinity compatible pair of antibodies was selected for the development of the assay. The standards were calibrated against the NIBSC, 1st IS (97/594) and the reference range measured in adult males, females and adolescents. Linearity for leptin was analyzed over a measured range of 4.30 to $45.90 \mathrm{ng} / \mathrm{mL}$ and the results were within an allowed systematic error of 5\%.

Serum samples were prepared by adding varying amounts of concentrated leptin solution containing a known amount of leptin. The threshold (lower limit of detection) was $0.0094 \mathrm{ng} / \mathrm{mL}$ and the recovery was in the $92-100 \%$ range, with a mean value of $99 \%$.

Monoclonal J3P3 was adsorbed to wells of microtiter plates overnight at $4^{\circ} \mathrm{C}$. Serum sample or standards $(100 \mu \mathrm{L})$ were added and incubated for $2 \mathrm{~h}$ at room temperature. The wells were washed and $200 \mathrm{~mL}$ of a solution containing monoclonal A7P2 la- beled with Europium was added, followed by 1-h incubation. After several washings, enhancement solution was added and fluorescence read in a time-resolved fluorometer (Perkin Elmer Life and Analytical Sciences, Wallac, Turkur, Finland). The assay is unaffected by bilirubin, hemolysis, triglycerides, or heterophile antibodies. The intra-assay coefficient of variation was $5.3 \%$ (mean concentration: $11.86 \mathrm{ng} / \mathrm{mL}$ ) and $4.0 \%$ (mean concentration: $9.52 \mathrm{ng} / \mathrm{mL}$ ) and the interassay coefficient of variation was $7.1 \%$ (mean concentration: $3.25 \mathrm{ng} / \mathrm{mL}$ ), $7.2 \%$ (mean concentration; $10.24 \mathrm{ng} / \mathrm{mL}$ ), and $4.7 \%$ (mean concentration; $21.96 \mathrm{ng} / \mathrm{mL}$ ).

For the determination of leptin, blood was collected into glass tubes without additives and centrifuged for $1 \mathrm{~h}$. Blood samples were drawn after patients had fasted for $8 \mathrm{~h}$. All patients had fasting blood samples taken between 8:00 and 9:00 am. Samples were taken and placed on ice before centrifugation and serum was immediately frozen and stored at $-25^{\circ} \mathrm{C}$. The sample was thawed just before analysis, which was carried out within 6 months of blood collection. Dose-response curves were run with every assay. The measurements were made in duplicate and the variation was less than $10 \%$.

Serum N-terminal pro-brain natriuretic peptide (NT-proBNP) levels were measured by immunoassay with detection by electrochemiluminescence (Roche Diagnostics, São Paulo, SP, Brazil) using $20 \mu \mathrm{L}$ of serum and polyclonal antibodies that detect epitopes in the N-terminal region (amino acids 1-76) of the proBNP (108 amino acids). Cross-reactivity with other natriuretic peptides (BNP, proANP1, CNP2) and the renin-angiotensin system was $<0.001 \%$ (data from the manufacturer). The assay was fully automated using the Elecsys 2010 automated analyzer (Roche Diagnostics).

For the NT-proBNP assay the coefficient of variation was $7.0 \%$ (mean concentration $57 \mathrm{pg} / \mathrm{mL}$ ) and the inter- and intra-assay variations were 4.0 and $2.6 \%$, respectively. 
Concentration ranged from 5 up to 35,000 $\mathrm{pg} / \mathrm{mL}$ (data from the manufacturer). The threshold (lower limit of detection) was 5 $\mathrm{pg} / \mathrm{mL}$.

Two-dimensional ECG complemented with M-mode and color Doppler recordings was obtained according to the recommendations of the American Society of Echocardiography. The following parameters were computed: LV thickness, LV internal enddiastolic dimension, LV internal end-systolic dimension, LV mass, LV mass index, and ejection fraction by the Teichholz method.

For statistical analysis, the Kruskal-Wallis and Dunn tests for unpaired data were used to compare mean leptin level between Chagas' disease and control subjects, with the level of significance set at $\mathrm{P}<0.05$.

Chagas' disease patients and healthy controls did not differ in age or BMI $(\mathrm{P}>0.3)$.

Table 1. Characteristics of patients with Chagas' disease and control subjects.

\begin{tabular}{lcccc}
\hline & $\begin{array}{c}\text { IF group } \\
(\mathrm{N}=24)\end{array}$ & $\begin{array}{c}\text { ECG group } \\
(\mathrm{N}=14)\end{array}$ & $\begin{array}{c}\text { CHF group } \\
(\mathrm{N}=14)\end{array}$ & $\begin{array}{c}\text { Controls } \\
(\mathrm{N}=30)\end{array}$ \\
\hline Age (years) & $48.4 \pm 10.8$ & $42.9 \pm 8.1$ & $47.8 \pm 9.1$ & $43.9 \pm 5.9$ \\
BMI $\left(\mathrm{kg} / \mathrm{m}^{2}\right)$ & $24.7 \pm 2.7$ & $23.2 \pm 3.1$ & $24.0 \pm 2.0$ & $24.6 \pm 2.2$ \\
Leptin $(\mathrm{ng} / \mathrm{mL})$ & $5.3 \pm 5.3$ & $9.7 \pm 10.7$ & $1.4 \pm 0.8^{*}$ & $8.1 \pm 7.8$ \\
NT-ProBNP $(\mathrm{pg} / \mathrm{mL})$ & $53.2 \pm 33.3$ & $83.3 \pm 57.4$ & $831.8 \pm 800.1^{*}$ & $32.0 \pm 22.7$ \\
LVSD $(\mathrm{cm})$ & $31.7 \pm 5.9$ & $31.4 \pm 3.5$ & $52.4 \pm 10.9^{*}$ & $31.3 \pm 4.2$ \\
LVEDV $(\mathrm{mL})$ & $116.1 \pm 40.8$ & $114.1 \pm 25.6$ & $273.4 \pm 137.2^{*}$ & $115.1 \pm 33.2$ \\
LVESV $(\mathrm{mL})$ & $35.2 \pm 21.2$ & $32.2 \pm 11.3$ & $161.6 \pm 109.8^{*}$ & $33.1 \pm 12.2$ \\
EF $(\%)$ & $0.71 \pm 0.07$ & $0.71 \pm 0.05$ & $0.44 \pm 0.12^{*}$ & $0.71 \pm 0.05$
\end{tabular}

Data are reported as means $\pm \mathrm{SD}$ for $\mathrm{N}$ subjects. $\mathrm{IF}=$ indeterminate form; $\mathrm{ECG}=$ electrocardiogram; $\mathrm{CHF}=$ congestive heart failure; $\mathrm{BMI}=$ body mass index; NTProBNP $=\mathrm{N}$-terminal pro-brain natriuretic peptide; LVSD = left ventricular systolic dimension; LVEDV = left ventricular end-diastolic volume; LVESV = left ventricular end-systolic volume; $E F$ = ejection fraction.

${ }^{*} \mathrm{P}<0.05$ compared to control (Kruskal-Wallis test).

Figure 1. Leptin levels in different forms of Chagas' disease. Data are reported as means \pm SD. ${ }^{*} P<0.05$ compared to other groups (Kruskal-Wallis test). IF = indeterminate form; ECG = electrocardiogram; $\mathrm{CHF}=$ congestive heart failure.

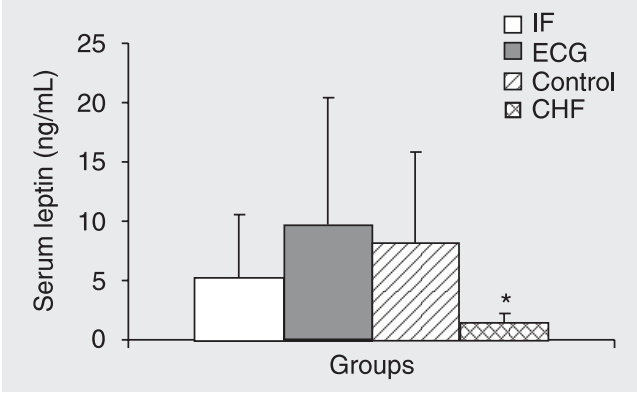

The CHF group had lower serum leptin levels $(\mathrm{P}<0.001)$ compared to controls and to the other chagasic groups. NT-proBNP levels were significantly higher $(\mathrm{P}<0.001)$ in the CHF group compared to other chagasic groups and control (Table 1 and Figure 1).

The study showed that patients with Chagas' disease and CHF had lower serum leptin levels, independently of age or parameters of body composition such as weight and BMI.

Leptin is a 167-amino acid cytokine synthesized and secreted from adipose tissue which functions as a signal of sufficiency of energy stores, and plasma leptin level is controlled by nutritional status. Several factors have been identified as regulators of leptin synthesis and release including the sympathetic nervous system, insulin and proinflammatory cytokines as well as glucocorticoids (6).

More recently, leptin has been designated as a potential biomarker of heart failure (6). In the present study, chagasic patients with the indeterminate form, ECG abnormalities, and heart failure had similar BMI; however, only the last group had a very low plasma leptin level. Usually leptin concentration is low during starvation and is increased by refeeding. In different studies, circulating levels of leptin were increased in non-cachectic heart failure patients and were normal-to-low in cachectic patients (10-12).

In the present study, plasma leptin was measured in chagasic patients and controls after $8 \mathrm{~h}$ of fasting. All subjects had a normal BMI and low circulating levels of leptin. Since heart failure in chagasic patients has a different mechanism than that of idiopathic $\mathrm{CHF}$, we speculate that the low leptin levels in these subjects have a cause other than simply the nutritional state. Leptin has a direct relation to sympathetic activity, and the release of this peptide is proportional to fat cell mass (13-15). This interaction between leptin and the sympathetic nervous system seems to be two-way, with leptin 
causing activation of central sympathetic outflow throughout the hypothalamus, resulting in stimulation of adrenal and medullary release of epinephrine (16), and with the sympathetic nervous system inhibiting leptin release from white adipose tissue (14).

Chagas' disease results in central nervous system damage and also in cardiac neuronal depopulation. The impaired cardiac sympathetic activity precedes wall motion impairment in Chagas' disease (17). We already know that the sympathetic nervous system acts regionally. Our speculation is that chagasic patients with heart failure have central nervous system injuries, cardiac neuronal depopulation, and increased sympathetic activity on white adipose tissue, resulting in a decrease in leptin synthesis and a release of white adipocyte cells. The increased degradation of leptin is another hypothesis that we have to consider. Further studies including different models of heart failure, in obese and non-obese patients with the evaluation of autonomic cardiac control (spectral analysis) should be conducted in order to test this hypothesis.

We believe that NT-proBNP belongs to a family of naturally occurring hormones known as natriuretic peptides. Synthesized in the cardiac ventricles, elevated plasma NT-proBNP levels are highly specific for elevated filling pressures in patients with LV dysfunction, and can provide relatively reliable diagnostic and prognostic information (18). High plasma NT-proBNP levels (usually above $400-500 \mathrm{pg} / \mathrm{mL}$ ) are related to a poor prognosis in patients with heart failure (19). In our study, plasma NT-proBNP in the heart failure group of chagasic patients was over $800 \mathrm{pg} / \mathrm{mL}$, suggesting a poor prognosis.

These findings are intriguing if, indeed, leptin is protective against the cardiosuppressive effects of TNF-1 or IL-1. By facilitating the decrease in circulating concentrations of leptin, cardiac cachexia may facilitate the downward spiral of cardiac decompensation effected by elevated amounts of TNF-1 or IL-1 (20). Finally, for the first time, it was demonstrated that patients with chagasic cardiomyopathy have low leptin levels, in contrast to those observed in other forms of heart failure (7).

We concluded that chagasic patients with heart failure have high levels of NT-ProBNP and low levels of leptin. We propose that leptin metabolism participates in advanced stage heart failure. One or more leptin-suppressing mechanisms may operate in chagasic patients. Further studies are needed to elucidate these facts.

\section{References}

1. Ianni BM, Arteaga E, Frimm CC, Pereira Barretto AC, Mady C. Chagas' heart disease: evolutive evaluation of electrocardiographic and echocardiographic parameters in patients with the indeterminate form. Arq Bras Cardiol 2001; 77: 59-62.

2. Dias JC. História natural. In: Cançado JR, Chuster M (Editors), Cardiopatia Chagásica. Belo Horizonte: Fundação Carlos Chagas; 1985. p 99-113.

3. Coura JR, de Abreu LL, Pereira JB, Willcox HP. Morbidity in Chagas' disease. IV. Longitudinal study of 10 years in Pains and Iguatama, Minas Gerais, Brazil. Mem Inst Oswaldo Cruz 1985; 80: 73-80.

4. Wolk R, Johnson BD, Somers VK. Leptin and the ventilatory response to exercise in heart failure. J Am Coll Cardiol 2003; 42: 1644-1649.

5. Grassi G. Leptin, sympathetic nervous system, and baroreflex func- tion. Curr Hypertens Rep 2004; 6: 236-240.

6. Schulze PC, Kratzsch J. Leptin as a new diagnostic tool in chronic heart failure. Clin Chim Acta 2005; 362: 1-11.

7. Schulze PC, Kratzsch J, Linke A, Schoene N, Adams V, Gielen S, et al. Elevated serum levels of leptin and soluble leptin receptor in patients with advanced chronic heart failure. Eur J Heart Fail 2003; 5: 33-40.

8. Richartz BM, Lotze U, Krack A, Gastmann A, Kuthe F, Figulla HR. Leptin: a parameter for metabolic changes in heart failure. $Z$ Kardiol 2001; 90: 280-285.

9. Soares Barreto-Filho JA, Consolim-Colombo FM, Ferreira LH, Martins Sobrinho CR, Guerra-Riccio GM, Krieger EM. Dysregulation of peripheral and central chemoreflex responses in Chagas' heart disease patients without heart failure. Circulation 2001; 104: 1792- 
1798.

10. Doehner W, Pflaum CD, Rauchhaus M, Godsland IF, Egerer K, Cicoira $M$, et al. Leptin, insulin sensitivity and growth hormone binding protein in chronic heart failure with and without cardiac cachexia. Eur J Endocrinol 2001; 145: 727-735.

11. Doehner W, Rauchhaus M, Godsland IF, Egerer K, Niebauer J, Sharma $\mathrm{R}$, et al. Insulin resistance in moderate chronic heart failure is related to hyperleptinaemia, but not to norepinephrine or TNFalpha. Int J Cardiol 2002; 83: 73-81.

12. Filippatos GS, Tsilias K, Venetsanou K, Karambinos E, Manolatos D, Kranidis A, et al. Leptin serum levels in cachectic heart failure patients. Relationship with tumor necrosis factor-alpha system. Int $J$ Cardiol 2000; 76: 117-122.

13. Ahima RS, Flier JS. Leptin. Annu Rev Physiol 2000; 62: 413-437.

14. Trayhurn P, Duncan JS, Hoggard N, Rayner DV. Regulation of leptin production: a dominant role for the sympathetic nervous system? Proc Nutr Soc 1998; 57: 413-419.

15. Donahoo WT, Jensen DR, Yost TJ, Eckel RH. Isoproterenol and somatostatin decrease plasma leptin in humans: a novel mechanism regulating leptin secretion. J Clin Endocrinol Metab 1997; 82: 4139-4143.

16. Elmquist JK, Maratos-Flier E, Saper CB, Flier JS. Unraveling the central nervous system pathways underlying responses to leptin. Nat Neurosci 1998; 1: 445-450.

17. Simões MV, Pintya AO, Sarabanda AV. Reduced [123I]MIBG uptake precedes wall motion impairment in Chagas' disease. J Nucl Cardiol 1999; 6: S63.

18. Richards AM. The natriuretic peptides in heart failure. Basic Res Cardiol 2004; 99: 94-100.

19. Hartmann F, Packer M, Coats AJ, Fowler MB, Krum H, Mohacsi P, et al. Prognostic impact of plasma $\mathrm{N}$-terminal pro-brain natriuretic peptide in severe chronic congestive heart failure: a substudy of the Carvedilol Prospective Randomized Cumulative Survival (COPERNICUS) trial. Circulation 2004; 110: 1780-1786.

20. Holycross BJ, Radin MJ. Cytokines in heart failure: potential interactions with angiotensin II and leptin. Mol Interv 2002; 2: 424-427. 